\title{
Exhaled Droplets Grow in Size on Cool Days
}

\author{
In cool, humid air, droplets emitted by a cough first grow then shrink, \\ according to simulations.
}

By David Ehrenstein

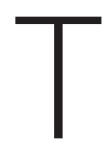

he COVID-19 pandemic has focused attention on the respiratory droplets produced by breathing, coughing, and singing. Numerical simulations of a cough now show [1] that in cooler, more humid air, these droplets first grow before evaporating and shrinking-they don't continuously evaporate, as previous research has suggested. The growth occurs when warm, humid breath interacts with colder air, producing a plume of water-vapor-saturated air-an effect that leads to the familiar "frosty" breath on cold days. The enlargement of cough droplets inside this plume causes them to survive longer than they do at higher temperatures, potentially allowing an infected person to spread an airborne disease to people located farther away.

In recent simulations [2], Detlef Lohse of the University of Twente in the Netherlands and his colleagues showed that the humid, turbulent jet of breath in a cough allows the smallest droplets (around 10 micrometers in diameter) to survive up to 150 times longer than they would in isolation. These results agreed with previous evidence that, indoors, the ubiquitous "6 foot rule" is not adequate to avoid contact with the smallest droplets expelled by an unmasked person (see How Talking
Spreads Viruses).

In their new simulations, the team varied both the ambient temperature and the ambient humidity. They found that for relative humidity of $90 \%$, the average droplet size increases for about 0.3 seconds if the ambient temperature is $10^{\circ} \mathrm{C}\left(50^{\circ} \mathrm{F}\right)$ but continuously decreases if it's $30^{\circ} \mathrm{C}$. The growth in the $10^{\circ} \mathrm{C}$ simulations is caused by condensation in a plume of air with local humidity above $100 \%$; at $30^{\circ} \mathrm{C}$, the air around the droplets is less humid. The team also developed a mathematical model that accurately predicts the local humidity changes and that could be used to predict the behavior of droplets.

David Ehrenstein is a Senior Editor for Physics.

\section{REFERENCES}

1. C. S. Ng et al., "Growth of respiratory droplets in cold and humid air," Phys. Rev. Fluids 6, 054303 (2021).

2. K. L. Chong et al., "Extended lifetime of respiratory droplets in a turbulent vapor puff and its implications on airborne disease transmission," Phys. Rev. Lett. 126, 034502 (2021). 

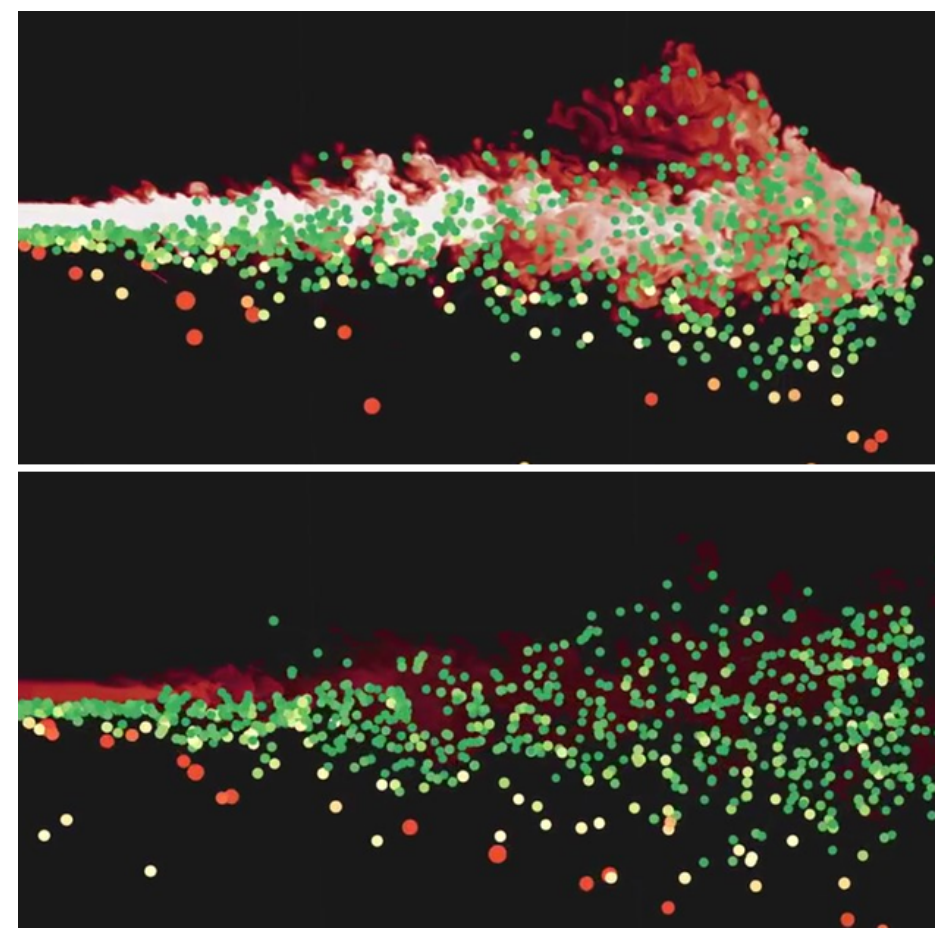

Cough comparison. Simulations of a cough at two ambient temperatures: $10^{\circ} \mathrm{C}$ (top) and $30^{\circ} \mathrm{C}$ (bottom)-see videos below. A plume of vapor-filled air surrounding the droplets has higher humidity (white) at the colder temperature, causing the droplets to grow. This initial growth allows droplets to survive in the air for a longer time before evaporating, compared with those in the $30^{\circ} \mathrm{C}$ simulation.

Credit: C. S. Ng et al. [1] 

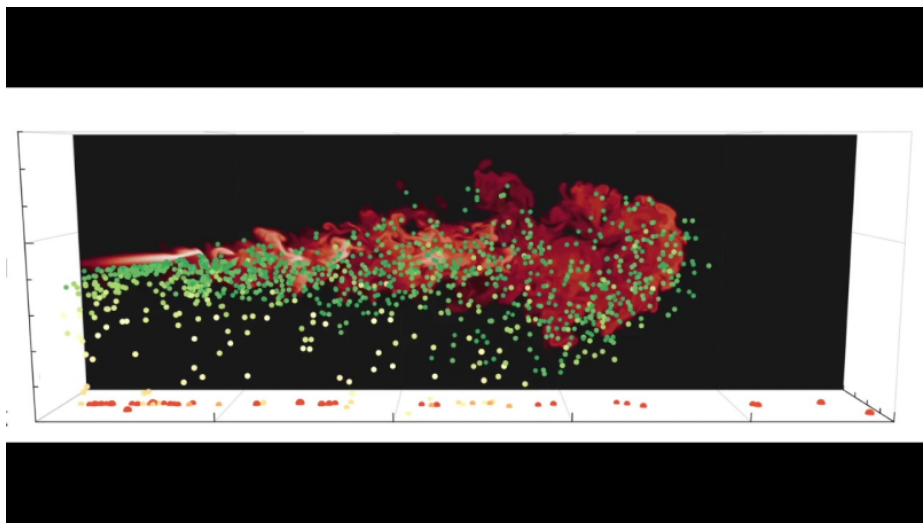

Simulation of a cough in ambient relative humidity of $90 \%$ and ambient temperature of $10^{\circ} \mathrm{C}$. The local relative humidity is shown with a color scale from dark red (90\%) to white (110\%), and the droplet diameters are shown with colors ranging from dark green (less than 10 micrometers) to dark red (100 micrometers). The video covers about 0.7 seconds of real time, and the field of view is $1 \mathrm{~m}$ wide. The white and pale red supersaturated region (humidity above $100 \%$ ) is not present at $30^{\circ} \mathrm{C}$ (see video below) and allows droplets to grow in size in their early moments (not obvious from these videos).

Credit: C. S. Ng et al. [1]
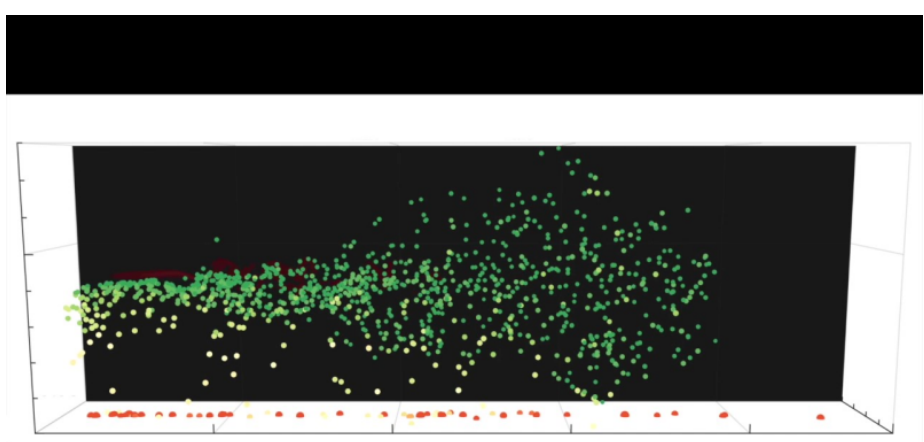

Same as above, but the ambient temperature is $30^{\circ} \mathrm{C}$.

Credit: C. S. Ng et al. [1] 